\title{
Using Multiple Index Comprehensive Method to Assess Urban Rainstorm Disaster Risk in Jiangsu Province, China
}

\author{
Junfei Chen $\mathbb{D}^{1,2,3}$ Mengchen Chen, ${ }^{1}$ and Pei Zhou ${ }^{1}$ \\ ${ }^{1}$ Business School, Hohai University, Nanjing 210098, China \\ ${ }^{2}$ Yangtze River Conservation and Green Development Institute, Hohai University, Nanjing 210098, China \\ ${ }^{3}$ Jiangsu Yangtze River Conservation and High-quality Development Research Center, Hohai University, Nanjing 210098, China
}

Correspondence should be addressed to Junfei Chen; chenjunfei@hhu.edu.cn

Received 21 December 2019; Revised 18 March 2020; Accepted 18 April 2020; Published 21 July 2020

Academic Editor: Luis Cea

Copyright ( $\odot 2020$ Junfei Chen et al. This is an open access article distributed under the Creative Commons Attribution License, which permits unrestricted use, distribution, and reproduction in any medium, provided the original work is properly cited.

An integrated index system for urban rainstorm risk evaluation has been developed. Meanwhile, an information diffusion method (IDM) and variable fuzzy sets (VFSs) were employed to evaluate the dangerousness, sensitivity, and vulnerability risk of urban rainstorm disasters, respectively. Then, the comprehensive risk zoning map was drawn. Finally, Jiangsu Province has been taken as a case study area. Due to heavy rainfall in short-term and low rainstorm resistance ability, Wuxi, Changzhou, Nanjing, and Suzhou have higher dangerousness while Wuxi, Changzhou, and Nanjing have higher sensitivity. And because of potential losses in urban rainstorm disaster, Wuxi and Suzhou have higher vulnerability than other cities. The comprehensive risk zoning map showed that most cities of Jiangsu Province are at the moderate risk level, and the northwestern cities have lower risk level than the southern cities. The results are consistent with the actual situation of Jiangsu Province, and the study can provide some decision-making references for the urban rainstorm management.

\section{Introduction}

With the global climate change and the rapid developments of the urbanization, many cities are suffered extreme rainstorm events frequently [1-4]. According to EM-DAT and Munich RE disaster databases, about $15 \%$ of the worldwide population is under the threat of the rainstorm disasters, and flood losses account for $28 \%$ of total global disaster losses. The more frequent urban rainstorm disasters in big cities have brought about severe economic losses $[5,6]$. In China, more than 600 cities are exposed to frequent floods, which have caused adverse influence on social, economic, environmental, and stability development $[7,8]$. Therefore, it is vital to evaluate urban rainstorm disaster risk, which can help to improve the prediction ability and to reduce the losses caused by urban rainstorm disasters.

In the last decades, several disaster risk assessment systems for urban rainstorm have been developed. Lyu [9] proposed a risk assessment system based on rainy season, average rainfall, river proximity, and other rainstorm indices. Alfa [10] developed a flood risk assessment system of Ofu River catchment in Nigeria, including elevation, slope, proximity, and soil type. Weerasinghe [11] put forward the risk assessment system of rainstorm for the Western Province of Sri Lanka. In the system, they adopted a statistical expression of hazard, exposure, and vulnerability to assess the combined flood risk levels. Chen [12] used the radial basis function (RBF) neural network to assess the urban flood risk of the Yangtze River Delta, China, during 2009 to 2018. In combination with urban plan and hydrologic data, Wang [13] developed a generalized risk assessment model of pipeline network. According to the 1302 historical sample data, Shao [14] adopted the gray fixed weight cluster analysis to assess the disaster losses from 2004 to 2009. These research studies laid a good foundation for the risk assessment index system of urban rainstorm disasters. Considering that urban rainstorm risk assessment involves hazard-formative factors, hazard-inducing environments, and hazard-affected body, this paper establishes the index system with dangerousness of hazard-formative factors, 
sensitivity of hazard-inducing environments, and vulnerability of hazard-affected body.

Meanwhile, GIS (the Geographic Information System) and remote-sensing imagery [15-18] are adopted to assess the risk assessment of urban rainstorm disasters. However, due to lack of sufficient data, urban rainstorm disasters are difficult to assess accurately [19]. Therefore, fuzzy and uncertainty theories were introduced into the risk assessment of urban rainstorm disasters. Ren [20] adopted variable fuzzy sets to assess the flood risk in Chengdu, China. Wang [21] evaluated the flood risk in Guizhou based on the information diffusion method. Zou [22] adopted information diffusion to analyze the flood risk. However, there are some drawbacks in the above methods. For example, the information diffusion method (IDM) cannot assess the subsystem risk in the rainstorm assessment while the variable fuzzy sets (VFSs) are difficult to determine the classification standards objectively [23]. Chen [24] showed that the IDM can help the VFS to establish the classification standards, and the VFS can obtain the subsystems and comprehensive risk evaluation results. Therefore, in this paper, a brand-new domain "the risk of urban rainstorm disasters" is studied. We build a new evaluation index system in this paper. Urban rainstorm is a fuzzy phenomenon and lack of sufficient data; traditional statistics are difficult to depict it accurately, especially in small sample problems. Therefore, some fuzzy and uncertainty theories have been developed to assess the risk of urban rainstorm disasters. The variable fuzzy sets (VFSs) can make full use of various index data to obtain comprehensive risk evaluation results. The information diffusion method (IDM) can transform a sample observed value into a fuzzy set and is capable of dealing with small sample problems. Meanwhile, IDM can extract useful information and establish the level classification standards of urban rainstorm disasters risk assessment indices, which is helpful to determine the relative membership function of the VFS. Therefore, in this research, the level classification standards of each risk assessment index of urban rainstorm disasters were calculated by the IDM, and then risks of dangerousness, sensitivity, and vulnerability were obtained by the VFS. Finally, Jiangsu Province in China was taken as a case study area.

\section{Overview of Study Area}

This paper takes Jiangsu Province as the study area. Jiangsu Province (Figure 1) is located between $116^{\circ} 18^{\prime} \mathrm{E}-121^{\circ} 57^{\prime} \mathrm{E}$ and $30^{\circ} 45^{\prime} \mathrm{N}-35^{\circ} 20^{\prime} \mathrm{N}$. The total area is $1.072 \times 10^{5} \mathrm{~km}^{2}$, accounting for $1.1 \%$ area of China. The geomorphology of Jiangsu is mainly plains and the elevation of most area is lower than $50 \mathrm{~m}$ [25]. There are 13 prefecture-level cities in Jiangsu Province, including Nanjing (provincial capital city), Wuxi, Xuzhou, Changzhou, Suzhou, Nantong, Lianyungang, Huai'an, Yancheng, Yangzhou, Zhenjiang, Taizhou, and Suqian. Jiangsu Province belongs to the subtropical monsoon climate, and thus, most of the large-scale precipitation is happed in summer. To better show the actual situations of the urban rainstorm disasters of Jiangsu
Province, this paper emphasizes research, the period from June to August.

Jiangsu Province is one of the most urbanized regions in China. In recent years, urban rainstorm disasters have occurred more frequently and caused huge losses in Jiangsu Province. Thus, urban rainstorm has become one of the most important factors that restrict the development of Jiangsu Province.

\section{Data and Methods}

3.1. Data Sources. This paper uses Jiangsu Statistical Yearbook data and China City Statistical Yearbook data to collect the statistical information of all cities in Jiangsu Province including economic, social, demographic, urban construction, environmental, and other related city statistics. The meteorological data and the rainfall statistics are collected from the meteorological stations of cities in Jiangsu Province. Other historical precipitation statistics are provided by the Jiangsu climate center. Among these data, the continuous rainfall days and heavy rain days are collected by monthly from 2010 to 2016 from the Jiangsu climate center.

3.2. Weight of Index System. The index weight reflects the relative importance of each index in the risk assessment index system. In this paper, the AHP (Analytic Hierarchy Process) and entropy weight are combined to calculate the weights of indices. The AHP is a subjective method to determine the weight of indices based on experts' experience [26]. The entropy weight method is an objective method that determines the importance of index based on the data information [27]. This combined method can reduce the interference of the individual's subjective judgments on the weights of indices. Therefore, it can make the weights more realistic and reliable relatively [28]. The idea of calculating weights is to calculate the subjective weights of indices by AHP and then to establish the entropy model of expert's own weights by using the subjective weights of indices as attribute matrices through the idea of information entropy. The weights of the indices are corrected by the weights of the experts, and the final combination weights are obtained.

Suppose the weights calculated by AHP are the subjective weights of indices. The subjective weights of indices can be represented as follows:

$$
W_{z}=\left(w_{z 1}, w_{z 2}, \ldots, w_{z r}\right)^{T}
$$

where $W_{z}$ is the subjective weight vector, $0<w_{z s}<1$, and $\sum_{s=1}^{r} w_{z s}=1(s=1,2, \ldots, r ; z=1,2, \ldots, v)$.

Then, the expert's own weights are calculated by the entropy weight method, and it can be calculated as follows:

$$
S=\left(S_{1}, S_{2}, \ldots, S_{v}\right)^{T},
$$

where the $S$ is expert's own weight vector, $0<S_{z}<1$ $(z=1,2, \ldots, v)$, and $\sum_{z=1}^{v} S_{z}=1$.

Finally, the weight fusion vector of subjective weights and expert's own weights can be expressed as $W=\left(w_{1}, w_{2}, \ldots, w_{r}\right)^{T}$. It can be calculated as follows: 


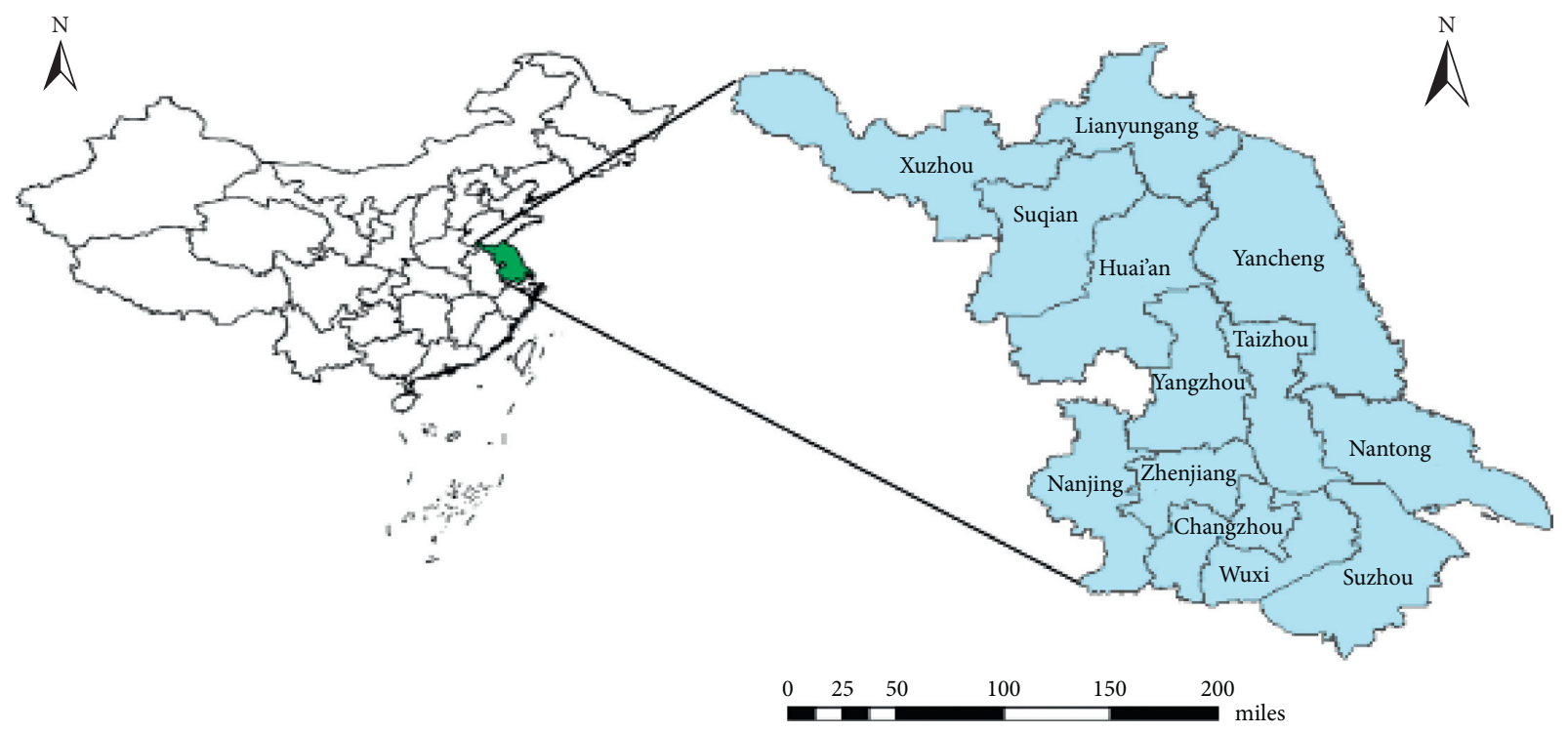

Figure 1: Geographic location of Jiangsu Province, China.

$$
w_{s}=\sum_{z=1}^{v}\left(w_{z s} \times S_{z}\right)
$$

where $0<w_{s}<1, \quad \sum_{s=1}^{r} w_{s}=1, \quad$ and $\quad s=1,2, \ldots, r ; z=$ $1,2, \ldots, v$.

3.3. Information Diffusion Method (IDM). IDM is a kind of a fuzzy mathematical processing method which can be used to optimize the fuzzy information of samples by means of an appropriate diffusion model [29]. When the sample is incomplete, the method can make the diffusion estimation closer to the real relationship than the nondiffusion estimation. It can establish the level classification standards of the urban rainstorm disasters assessment indices to improve the evaluation accuracy [30]. Based on the historical data of Jiangsu province, the different risk levels of indices were determined according to classification standards.

The principle of the information diffusion method can be expressed as follows: suppose $X\left(X=\left\{x_{1}, x_{2}, \ldots, x_{n}\right\}\right)$ is a sample and it can be used to estimate a relationship on a domain $U$. When the $X$ is incomplete, there exist an appropriate diffusion function $f\left(x_{i}, u\right)$ and the corresponding operator $\gamma^{\prime}$, which can transform $X$ into a fuzzy sample $D(X)$; thus, the information with a value of 1 from the sample $X$ can be diffused around the sample following the function $f\left(x_{i}, u\right)$, and the diffusion estimate $\widetilde{R}$ is closer to the real relationship than the nondiffusion estimate $\widehat{R}$ [31-33]. It can be shown in Figure 2.

The calculation steps of the information diffusion are as follows:

Firstly, the risk levels of urban rainstorm disasters are divided into five levels, i.e., lowest risk, lower risk, moderate risk, higher risk, and highest risk. The information carried by $x_{i}(i=1,2, \ldots, n)$ can be diffused into $u_{j}(j=1,2, \ldots, m)$ from the domain $U$ according to the following equation:

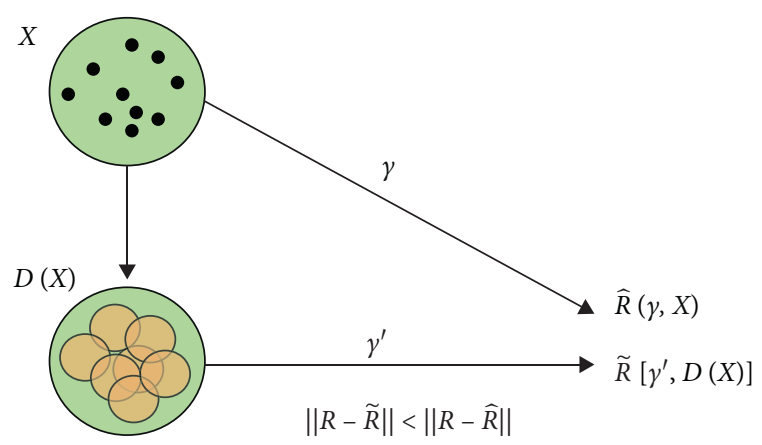

FIgURE 2: The principle of the information diffusion method.

$$
f_{i}\left(u_{j}\right)=\frac{1}{h \sqrt{2 \pi}} \exp \left[-\frac{\left(x_{i}-u_{j}\right)}{2 h^{2}}\right],
$$

where $h$ is the diffusion coefficient, which can be calculated by different sizes and the sample values.

Secondly, in order to make each set of sample values identical, the diffusion function $f_{i}\left(u_{j}\right)$ is normalized to be the diffusion function $g_{i}\left(u_{j}\right)$ :

$$
g_{i}\left(u_{j}\right)=\frac{f_{i}\left(u_{j}\right)}{\sum_{j=1}^{m} f_{i}\left(u_{j}\right)} .
$$

The probability of samples located in $u_{j}$ can be represented as follows:

$$
F\left(u_{j}\right)=\frac{\sum_{i=1}^{n} g_{i}\left(u_{j}\right)}{\sum_{j=1}^{m} \sum_{i=1}^{n} g_{i}\left(u_{j}\right)} .
$$

Finally, the exceeding probability $F^{*}\left(u_{j}\right)$ can be obtained through the following equation:

$$
F^{*}\left(u_{j}\right)=\sum_{k=j}^{m} F\left(u_{k}\right) .
$$


According to the classification standards of exceeding probability, the critical value of each evaluation index corresponding to the risk level of urban rainstorm is obtained, so the level classification standards of urban rainstorm risk assessment indices can be obtained.

3.4. Variable Fuzzy Set (VFS). Variable fuzzy set theory is mainly used in the dynamic analysis of fuzzy phenomena [34]. As its core, relative membership function, relative difference function, and variable fuzzy set quantify the process of changing things from quantity to quality and describe it with mathematical languages. By changing the model and model parameters, the credibility and reliability of evaluation, identification, and decision-making can be increased, which provides new ideas for risk assessments in many fields [35, 36].

Fuzzy variable evaluation method calculates the evaluation level of urban rainstorm disasters scientifically by changing the model and its parameter combination, and it can improve the reliability of risk assessment results. The fuzzy variable evaluation method mainly includes the following steps:

(1) Generating index eigenvalue matrix

Suppose there is a sample set $Y=\left\{y_{1}, y_{2}, \cdots, y_{n}\right\}$ consisting of $n$ samples of natural disasters. The index eigenvalue of the sample $i$ can be expressed as $y_{i}=\left(y_{1 i}, y_{2 i}, \ldots, y_{r i}\right)^{T}$, where $r$ is the number of sample indices. Then, the sample set can be express as $Y=\left(y_{s i}\right)_{r \times n}$, where $s=1,2, \ldots, r ; i=1,2, \ldots, n$.

(2) Establishing index standard eigenvalue matrix

Suppose there are $m$ levels of assessment classification standards. And the sample set is identified according to different standards of eigenvalues of $r$ sample indices, and then the standard eigenvalue matrix of the first order index is obtained.

(3) Calculating the relative membership matrix of index level

The interval matrix and the bound matrix of variable set of indices can be determined by referring to the standard value matrix of indices and the actual situation of the area. Then, according to the different eigenvalues of samples $y_{s i}$, the different degree $L_{A}\left(y_{s i}\right)$, the relative membership degree matrix can be calculated as follows:

$$
\mu_{A}\left(y_{s i}\right)=\frac{1+L_{A}\left(y_{s i}\right)}{2}
$$

(4) Determining the weight of each index and the relative membership degree

According to equation (8), the nonnormalized relative membership degree can be calculated as follows:

$$
T_{h i}^{*}=\left\{1+\left[\frac{\sum_{s=1}^{r}\left[w_{s}\left(1-\mu_{A}\left(y_{s i}\right)\right)\right]}{\sum_{s=1}^{r}\left[w_{s} \mu_{A}\left(y_{s i}\right)\right]^{P}}\right]^{\alpha / P}\right\}^{-1},
$$

where $w_{s}(s=1,2, \ldots, r)$ is the index weight that can be calculated by equation (3). And $r$ is the identify number of indices, $h$ is the risk level number where $h=1,2, \ldots, m, \alpha$ is the optimal rule parameter $(\alpha=1,2), P$ is the distance parameter, $P=1$ is Hamming distance, and $P=2$ is Euclidean distance. Then, the normalized relative membership degree can be calculated as follows:

$$
T_{h_{i}}=\frac{T_{h i}^{*}}{\sum_{h=1}^{m} T_{h i}^{*}} .
$$

Finally, according to the principle of the largest degree of membership, we can obtain the risk levels of urban rainstorm disasters.

\section{Results and Analysis}

4.1. Risk Index System of Urban Rainstorm. In this paper, an integrated risk assessment index system of urban rainstorm disasters was established (see Table 1). The index system is divided into three subsystems including dangerousness, sensitivity, and vulnerability.

The dangerousness indices reflect the abnormal conditions and factors of external natural environment. The risk of urban rainstorm disasters can be attributed to short-term rainfall far exceeding normal situations or long-term rainfall in cities, which will lead to the arranged discharge of rainwater beyond the capacity of urban drainage network. Generally, the larger the dangerousness is, the higher the risk of urban rainstorm disasters is. This paper chooses continuous rainfall days ( $I_{11}$ : days), heavy rain days $\left(I_{12}\right.$ : days), maximum rainfall in $24 \mathrm{~h}\left(I_{13}: \mathrm{mm}\right)$, monthly total rainfall $\left(I_{14}: \mathrm{mm}\right)$, and precipitation anomaly percentage $\left(I_{15}: \%\right)$ as the evaluation indices of dangerousness.

The sensitivity indices represent that a particular region is potential to the destruction and influence of disasters due to various natural and social factors [37]. Jiangsu Province is located in the plain area with low altitude, and it is easy to cause floods once it encounters rainstorms. And rapid urbanization leads to the change of urban surface attributes. The urban surface is mostly impervious and hardened surface, which leads to the rapid convergence of surface rainwater under extreme rainstorms. The construction of drainage pipeline network in cities also has not kept pace with the development of the city. So, the urban average elevation $\left(I_{21}: \mathrm{m}\right)$, urban green coverage rate $\left(I_{22}: \%\right)$, urban drainage network density $\left(I_{23}: \mathrm{km} / \mathrm{km}^{2}\right)$, urban water area percentage $\left(I_{24}: \%\right)$, and impermeable construction land $\left(I_{25}\right.$ : $\mathrm{km}^{2}$ ) were selected as the sensitivity indices.

The vulnerability indices describe the potential losses of the area exposed to the risk [38]. It refers to the possible impact of urban rainstorm disasters in the urban, that is, the level of loss caused by urban rainstorm. It is generally believed that densely populated, industrially developed cities suffer greater risks and losses in face of the urban rainstorm disasters. The vulnerability indices include the density of 
TABLE 1: Risk assessment index system of urban rainstorm disaster.

\begin{tabular}{|c|c|c|}
\hline Target layer & Primary indices & Secondary indices \\
\hline Urban rainstorm disaster risk & Sensitivity & $\begin{array}{c}\text { Continuous rainfall days ( } I_{11}: \text { days) (monthly) } \\
\text { Heavy rain days }\left(I_{12}: \text { days) (monthly) }\right. \\
\text { Maximum rainfall in } 24 \mathrm{~h}\left(I_{13}: \mathrm{mm}\right) \\
\text { Monthly total rainfall }\left(I_{14}: \mathrm{mm}\right) \\
\text { Precipitation anomaly percentage }\left(I_{15}: \%\right) \\
\text { Urban average elevation }\left(I_{21}: \mathrm{m}\right) \\
\text { Urban green coverage rate }\left(I_{22}: \%\right) \\
\text { Urban drainage network density }\left(I_{23}: \mathrm{km} / \mathrm{km}^{2}\right) \\
\text { Urban water area percentage }\left(I_{24}: \%\right) \\
\text { Impermeable construction land }\left(I_{25}: \mathrm{km}^{2}\right) \\
\text { Density of affected population }\left(I_{31}: \text { People } / \mathrm{km}^{2}\right) \\
\text { GDP of unit area }\left(I_{32}: 100 \text { million yuan } / \mathrm{km}^{2}\right) \\
\text { Disaster relief investment level }\left(I_{33}: \%\right) \\
\text { Public emergency response capability }\left(I_{34}\right)\end{array}$ \\
\hline
\end{tabular}

affected population $\left(I_{31}\right.$ : people $\left./ \mathrm{km}^{2}\right)$, GDP of unit area $\left(I_{32}\right.$ : 100 million yuan $\left./ \mathrm{km}^{2}\right)$, disaster relief investment level $\left(I_{33}\right.$ : $\%$ ), and public emergency response capability $\left(I_{34}\right)$. The public emergency response capability $\left(I_{34}\right)$ can be quantified by expert scoring. Some experts are asked to score the index, and the average score is calculated as the index value.

4.2. Risk Evaluation Based on IDM-VFS Model. Based on the risk assessment index system and IDM-VFS model, firstly the AHP was combined with the entropy method to determine the weights of the risk indices of urban rainstorm disasters; secondly, the IDM was adopted to determine the classification standards of the risk indices; thirdly, the disaster risk values in dangerousness, sensitivity, and vulnerability can be calculated by the VFS model, respectively. Finally, the comprehensive disaster risk levels were obtained and the risk zoning map was drawn.

4.2.1. Determination of the Weights of Risk Indices. Index weights are determined by combined AHP and the entropy weight method. The weights of risk assessment indices are shown in Table 2.

4.2.2. Calculation of the Level Classification Standards of Indices. The level classification standards of each risk assessment index of urban rainstorm disasters are determined by IDM. Firstly, the index values can be taken as samples of information diffusion, then the exceeding probability of each index also can be calculated. Finally, the level classification standards of each risk assessment secondary index are obtained (see Table 3).

4.2.3. Calculation of the Disaster Risks of Three Subsystems. According to Table 3, the interval matrix and bound matrix are established, then, based on equations (8)-(10), the relative membership degree matrix and integrated membership degree are obtained, and finally, the risk values can be calculated in terms of dangerousness, sensitivity, and vulnerability, respectively. For demonstration purposes, Nanjing has been chosen as an example to discuss the risk
TABLE 2: The index weights of urban rainstorm disasters.

\begin{tabular}{|c|c|c|}
\hline $\begin{array}{l}\text { Primary } \\
\text { indices }\end{array}$ & Secondary indices & $\begin{array}{c}\text { Weight } \\
\omega_{i}\end{array}$ \\
\hline \multirow{5}{*}{ Dangerousness } & Continuous rainfall days (days) & 0.0630 \\
\hline & Heavy rain days (days) & 0.0735 \\
\hline & Maximum rainfall in $24 \mathrm{~h}(\mathrm{~mm})$ & 0.0945 \\
\hline & Monthly total rainfall (mm) & 0.0665 \\
\hline & Precipitation anomaly percentage (\%) & 0.0425 \\
\hline \multirow{5}{*}{ Sensitivity } & Urban average elevation $(\mathrm{m})$ & 0.0772 \\
\hline & Urban green coverage rate $(\%)$ & 0.0577 \\
\hline & $\begin{array}{l}\text { Urban drainage network density } \\
\qquad\left(\mathrm{km} / \mathrm{km}^{2}\right)\end{array}$ & 0.0927 \\
\hline & Urban water area percentage (\%) & 0.0735 \\
\hline & Impermeable construction land $\left(\mathrm{km}^{2}\right)$ & 0.1279 \\
\hline \multirow{4}{*}{ Vulnerability } & $\begin{array}{l}\text { Density of affected population (people/ } \\
\qquad \mathrm{km}^{2} \text { ) }\end{array}$ & 0.0424 \\
\hline & $\begin{array}{l}\text { GDP of unit area (100 million yuan/ } \\
\left.\qquad \mathrm{km}^{2}\right)\end{array}$ & 0.0916 \\
\hline & Disaster relief investment level (\%) & 0.0452 \\
\hline & Public emergency response capability & 0.0408 \\
\hline
\end{tabular}

assessment of urban rainstorm disasters in detail. The risk values of urban rainstorm disasters in Nanjing in 2016 are shown in Table 4.

From Table 4, dangerousness indices have different risk values due to different monthly rainfall and rainfall days. Sensitivity and vulnerability indices remain basically unchanged in one year, while the urban average elevation, urban green coverage rate, and impermeable construction land can be changed in a period time. So, sensitivity and vulnerability indices could change in many years. Adopting the same methods and procedures, we can obtain risk values of the urban rainstorm in Nanjing from 2010 to 2016 in terms of dangerousness, sensitivity, and vulnerability, respectively (see Table 5).

From Table 5, the average risk value of dangerousness is 3.48 , the average risk value of sensitivity is 3.72 , and the average risk value of vulnerability is 2.82 . The dangerousness of 2011 is higher than other years because the precipitation 
TABLE 3: Level classification standards of risk assessment secondary indices.

\begin{tabular}{|c|c|c|c|c|c|}
\hline Secondary indices & $\begin{array}{c}\text { First level } \\
\text { (lowest) }\end{array}$ & $\begin{array}{c}\text { Second level } \\
\text { (lower) }\end{array}$ & $\begin{array}{l}\text { Third level } \\
\text { (moderate) }\end{array}$ & $\begin{array}{c}\text { Forth level } \\
\text { (higher) }\end{array}$ & $\begin{array}{c}\text { Fifth level } \\
\text { (highest) }\end{array}$ \\
\hline Continuous rainfall days (days) & $<1$ & $1 \sim 2$ & $2 \sim 4$ & $4 \sim 6$ & $>6$ \\
\hline Heavy rain days (days) & $<1$ & $1 \sim 3$ & $3 \sim 5$ & $5 \sim 7$ & $>7$ \\
\hline Maximum rainfall in $24 \mathrm{~h}(\mathrm{~mm})$ & $<25$ & $25 \sim 50$ & $50 \sim 100$ & $100 \sim 200$ & $>200$ \\
\hline Monthly total rainfall $(\mathrm{mm})$ & $<50$ & $50 \sim 124$ & $124 \sim 236$ & $236 \sim 378$ & $>378$ \\
\hline Precipitation anomaly percentage (\%) & $<4$ & $4 \sim 15$ & $15 \sim 40$ & $40 \sim 100$ & $>100$ \\
\hline Urban average elevation $(\mathrm{m})$ & $>35$ & $35 \sim 20$ & $20 \sim 10$ & $10 \sim 5$ & $<5$ \\
\hline Urban green coverage rate $(\%)$ & $>50$ & $50 \sim 40$ & $40 \sim 30$ & $30 \sim 20$ & $<20$ \\
\hline Urban drainage network density $\left(\mathrm{km} / \mathrm{km}^{2}\right)$ & $>32$ & $32 \sim 24$ & $24 \sim 16$ & $16 \sim 10$ & $<10$ \\
\hline Urban water area percentage $(\%)$ & $>30$ & $30 \sim 20$ & $20 \sim 15$ & $15 \sim 10$ & $<10$ \\
\hline Impermeable construction land $\left(\mathrm{km}^{2}\right)$ & $<90$ & $90 \sim 148$ & $148 \sim 245$ & $245 \sim 440$ & $>440$ \\
\hline Density of affected population (people $/ \mathrm{km}^{2}$ ) & $<1265$ & $1265 \sim 2355$ & $2355 \sim 3375$ & $3375 \sim 4430$ & $>4430$ \\
\hline GDP of unit area $\left(100\right.$ million yuan $\left./ \mathrm{km}^{2}\right)$ & $<0.8$ & $0.8 \sim 1.2$ & $1.2 \sim 3$ & $3 \sim 5$ & $>5$ \\
\hline Disaster relief investment level (\%) & $>17$ & $15 \sim 17$ & $13 \sim 15$ & $9 \sim 13$ & $<9$ \\
\hline Public emergency response capability & $>90$ & $90 \sim 80$ & $80 \sim 70$ & $70 \sim 60$ & $<60$ \\
\hline
\end{tabular}

Table 4: Risk values from June to August in 2016 in Nanjing.

\begin{tabular}{lccc}
\hline Month & Dangerousness & Sensitivity & Vulnerability \\
\hline June & 4.11 & 3.82 & 2.87 \\
July & 4.21 & 3.82 & 2.85 \\
August & 2.46 & 3.82 & 2.88 \\
Average & 3.59 & 3.82 & 2.87 \\
\hline
\end{tabular}

TABLE 5: Risk values of urban rainstorm from 2010 to 2016 in Nanjing.

\begin{tabular}{lccc}
\hline Year & Dangerousness & Sensitivity & Vulnerability \\
\hline 2010 & 3.44 & 3.64 & 2.78 \\
2011 & 3.75 & 3.66 & 2.78 \\
2012 & 3.46 & 3.68 & 2.81 \\
2013 & 3.32 & 3.68 & 2.76 \\
2014 & 3.21 & 3.73 & 2.84 \\
2015 & 3.61 & 3.79 & 2.86 \\
2016 & 3.59 & 3.82 & 2.87 \\
Average & 3.48 & 3.72 & 2.82 \\
\hline
\end{tabular}

was higher than the average level (Figure 3(a)). According to historical data collected from the meteorological stations of cities in Jiangsu Province, it had sustained rainfall and strong rainfall intensity in short duration. Blanc et al. [10] showed that intense direct rainfall can overwhelm urban drainage systems and cause complex and often localised patterns of pluvial flooding. In terms of statistic, the weight and relative membership degree of maximum rainfall in $24 \mathrm{~h}$ and heavy rain days are higher than other dangerousness indications. So, "sustained rainfall and strong rainfall intensity in short duration" is the main reason for affecting dangerousness. Due to the acceleration of urbanization, the reduction of green area cause impermeable construction land increase, so the sensitivity and vulnerability had an upward tendency (Figures 3(b) and 3(c)). While the impervious construction area of the cities, the density of the affected population, and GDP are gradually increasing from 2010 to 2016, the drainage facilities and greening constructions are not growing responsively.
By calculating the average risk values in different cities in terms of dangerousness, sensitivity, and vulnerability, the risk levels of urban rainstorm disasters are shown in Table 6.

The dangerousness of Wuxi, Changzhou, Nanjing, and Suzhou is higher, while that of Xuzhou, Huai'an, and Suqian is lower from 2010 to 2016 . The major influence factors of dangerousness are sustained rainfall and strong rainfall intensity in short duration. And the precipitation decreased from south to north gradually.

The sensitivity of Wuxi, Changzhou, and Nanjing is higher, while that of Xuzhou and Suqian is lower. The sensitivity of urban rainstorm disasters mainly depends on the natural and social environment of the cities and the disaster resistance level. The conditions of the different cities in Jiangsu Province are uneven. Because different cities have different natural and social environments, Zhenjiang, Xuzhou, and Suqian have higher altitudes and less impervious construction area which makes them have lower sensitivity. Wuxi, Changzhou, and Nanjing are more advanced, so they have more impervious construction area which decreased the ability of disaster resistance, resulting in higher sensitivity [39].

Lianyungang, Yancheng, and Suqian are located in the lowest vulnerability area, while Wuxi and Suzhou are the highest cities. The vulnerability of urban rainstorm is the reflection of the vulnerable degree of social economy and human society capability to disasters. Lianyungang, Yancheng, and Suqian have lower GDP of unit area and affected population density so they belong to the lower disaster vulnerability cities. The GDP of unit area in Wuxi and Suzhou is more than 500 million (yuan $/ \mathrm{km}^{2}$ ), and the population density is higher, leading to the highest urban rainstorm vulnerability. Hurlbert and Dhakal $[40,41]$ both considered social economy and human society capability to disasters are the main reason for affecting vulnerability.

The comparisons of different cities in terms of dangerousness, sensitivity, and vulnerability, respectively, in Jiangsu Province are shown in Figure 4.

Based on the assessment results, the comprehensive risk zoning map in Jiangsu Province can be drawn (Figure 5). From Figure 5, it can be seen that the comprehensive risks of 


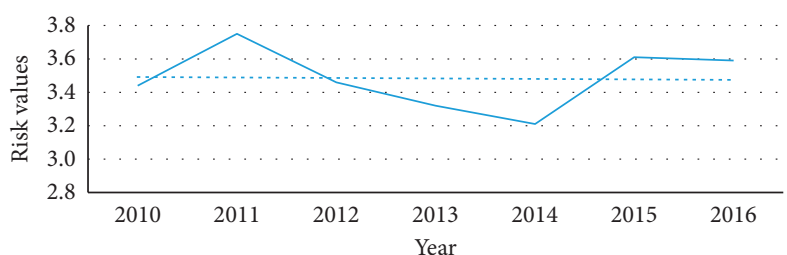

(a)

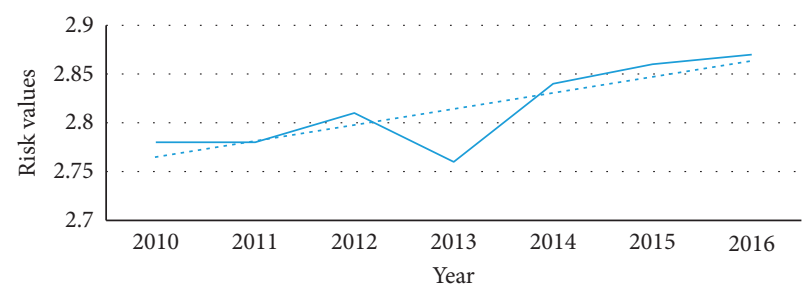

(b)

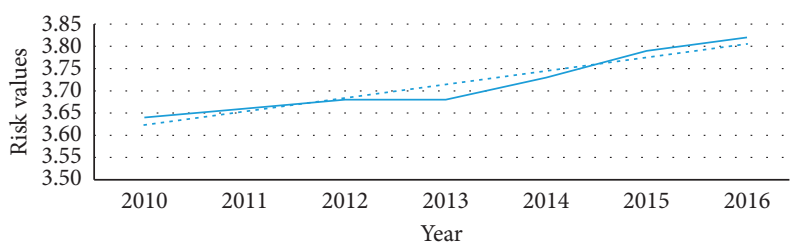

(c)

FIgURE 3: Variation tendency of risk values in terms of three subsystems from 2010 to 2016: (a) dangerousness; (b) sensitivity; (c) ulnerability.

Table 6: Comprehensive risk level in Jiangsu Province.

\begin{tabular}{|c|c|c|c|c|}
\hline City & Dangerousness & Sensitivity & Vulnerability & Risk level \\
\hline Nanjing & 3.48 & 3.72 & 2.82 & 4 \\
\hline Wuxi & 3.67 & 3.46 & 3.37 & 4 \\
\hline Xuzhou & 2.47 & 2.39 & 2.53 & 2 \\
\hline Changzhou & 3.62 & 3.58 & 3.03 & 4 \\
\hline Suzhou & 3.53 & 3.07 & 3.26 & 3 \\
\hline Nantong & 3.28 & 2.71 & 3.08 & 3 \\
\hline Lianyungang & 2.81 & 2.98 & 2.33 & 3 \\
\hline Yancheng & 2.83 & 2.74 & 2.46 & 3 \\
\hline Yangzhou & 3.02 & 2.45 & 2.87 & 3 \\
\hline Zhenjiang & 3.17 & 2.34 & 3.06 & 3 \\
\hline Taizhou & 2.86 & 2.57 & 2.94 & 3 \\
\hline Huai'an & 2.57 & 2.69 & 2.66 & 3 \\
\hline Suqian & 2.63 & 2.08 & 2.47 & 2 \\
\hline
\end{tabular}

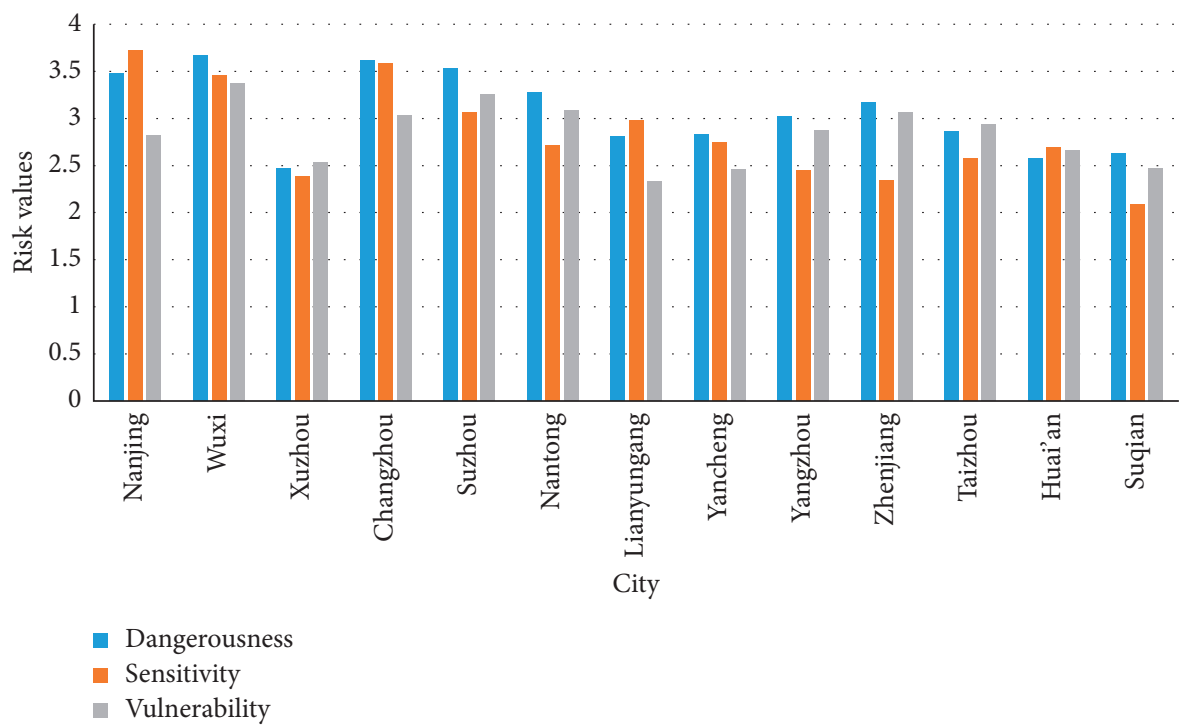

FIGURE 4: Comparisons of different cities in terms of dangerousness, sensitivity, and vulnerability, respectively, in Jiangsu Province. 


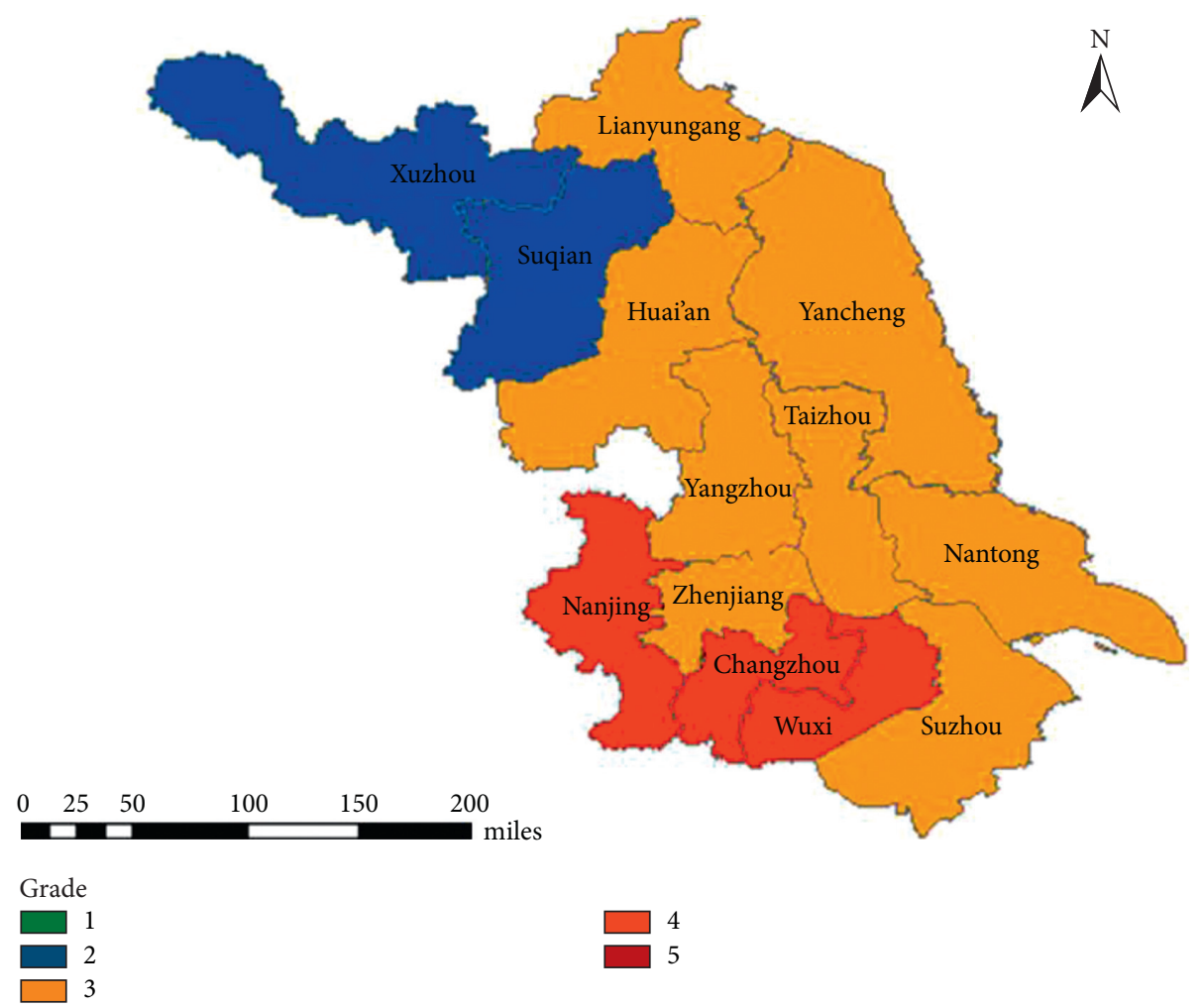

Figure 5: Distribution of urban rainstorm risk in Jiangsu Province.

urban rainstorm in Jiangsu Province have apparent regional characteristics. The comprehensive risk levels of urban rainstorm in Wuxi, Changzhou, and Nanjing are higher, while those of Xuzhou and Suqian are lower. The risk levels in the northwestern cities are lower than the southern cities in the Jiangsu Province. Moreover, most cities of Jiangsu Province experience moderate risk level.

\section{Discussion and Conclusions}

Urban rainstorm risk assessment involves many factors; thus, this paper established an integrated index system in terms of dangerousness of hazard-formative factors, sensitivity of hazard-inducing environments, and vulnerability of hazardaffected body. Then, the IDM and VFS models were coupled to assess the comprehensive risk of the urban rainstorm. In the coupled model, the IDM was adopted to determine the classification standards of the VFS. The assessment results of Jiangsu Province showed that most cities are at the moderate risk level, and the northwestern cities have lower risk than southern cities. In the dangerousness subsystem, due to the heavy rainfall in short-term, Wuxi, Changzhou, Nanjing, and Suzhou have higher risk than Xuzhou, Huai'an, and Suqian from 2010 to 2016. In the sensitivity subsystem, because of low urban rainstorm resistance capability, Wuxi, Changzhou, and Nanjing have higher risk than other cities. In the vulnerability subsystem, Wuxi and Suzhou have higher risk while Liangyungang, Yanchang, and Suqian have lower risk. The assessment results can help the local government to improve the rainstorm resistance capability and reduce the losses caused by rainstorm disasters.
In this paper, Jiangsu Province is a typical city suffering from frequent urban rainstorm disasters in recent years. According to the characteristics of regional urban rainstorm disasters, the risk assessment index system of urban rainstorm disasters is constructed. Based on the IDM and VFS model, the risk assessment model is established to assess the risk of rain and flood disasters in 13 cities of Jiangsu Province from 2010 to 2016. Then, according to the assessment results, the risk map of urban rainstorm disaster is drawn by ArcGIS and the assessment results are analyzed. Finally, the corresponding control measures are put forward which can provide decision-making reference for Jiangsu Province and other cities.

\section{Data Availability}

The continuous rainfall days, heavy rain days, maximum rainfall in $24 \mathrm{~h}$, monthly total rainfall, precipitation anomaly percentage, the urban average elevation, urban green coverage rate, urban drainage network density, urban water area percentage, impermeable construction land, the density of affected population, GDP of unit area, disaster relief investment level, and public emergency response capability data used to support the findings of this study are available from the corresponding author upon request.

\section{Conflicts of Interest}

The authors declare that there are no conflicts of interest regarding the publication of the paper. 


\section{Acknowledgments}

This research was supported by the National Key Research and Development Program of China (grant no. 2019YFC0409000), the National Natural Science Foundation of China (grant no. 41877526), the Fundamental Research Funds for the Central Universities (grant no. B200204018), the Water Conservancy Science and Technology Project of Jiangsu Province (grant no. 2017060), and the Humanities and Social Sciences Fund of Ministry of Education of China (grant no. 18YJA630009).

\section{References}

[1] X. H. He and W. F. Hu, "A two-stage queue model to optimize layout of urban drainage system considering extreme rainstorms," Mathematical Problems in Engineering, vol. 2017, Article ID 6380521, 18 pages, 2017.

[2] S. H. A. Koop and C. J. Van Leeuwen, "The challenges of water, waste and climate change in cities," Environment, Development and Sustainability, vol. 19, no. 2, pp. 385-418, 2017.

[3] A. Jerneck and L. Olsson, "Structuring sustainability science," Sustainability Science, vol. 6, no. 1, pp. 69-82, 2011.

[4] D. L. T. Hegger, P. P. J. Driessen, C. Dieperink, M. Wiering, G. T. T. Raadgever, and H. F. M. W. Van Rijswick, "Assessing stability and dynamics in flood risk governance," Water Resources Management, vol. 28, no. 12, pp. 4127-4142, 2014.

[5] R. Quan, "Risk assessment of flood disaster in Shanghai based on spatial-temporal characteristics analysis from 251 to 2000," Environmental Earth Sciences, vol. 72, no. 11, pp. 4627-4638, 2014.

[6] Z. Huang, J. Zhou, L. Song, Y. Lu, and Y. Zhang, "Flood disaster loss comprehensive evaluation model based on optimization support vector machine," Expert Systems with Applications, vol. 37, no. 5, pp. 3810-3814, 2010.

[7] S. M. Liu, H. Wang, D. Yan, Q. Ren, D. Wang, and B. Gong, "Analysis of spatiotemporal evolution of isolated rainstorm events in Huai river basin, China," Advances in Meteorology, vol. 2017, Article ID 3010295, 17 pages, 2017.

[8] D. Zhang and L. Wang, "Research on urban emergency management in Beijing based on complex system theory," City, vol. 4, pp. 49-53, 2016.

[9] H.-M. Lyu, W.-J. Sun, S.-L. Shen, and A. Arulrajah, "Flood risk assessment in metro systems of mega-cities using a GISbased modeling approach," Science of the Total Environment, vol. 626, pp. 1012-1025, 2018.

[10] M. I. Alfa, M. A. Ajibike, and R. E. Daffi, "Application of analytic hierarchy process and geographic information system techniques in flood risk assessment: a case of Ofu river catchment in Nigeria," Journal of Degraded and Mining Lands Management, vol. 5, no. 4, pp. 1363-1372, 2018.

[11] K. M. Weerasinghe, H. Gehrels, N. M. S. I. Arambepola, H. P. Vajja, J. M. K. Herath, and K. B. Atapattu, "Qualitative flood risk assessment for the Western Province of Sri Lanka," Procedia Engineering, vol. 212, pp. 503-510, 2018.

[12] J. F. Chen, Q. Li, H. M. Wang, and M. H. Deng, "A machine learning ensemble approach based on random forest and radial basis function neural network for risk evaluation of regional flood disaster: a case study of the Yangtze river Delta, China," International Journal of Environmental Research and Public Health, vol. 17, no. 1, p. 49, 2019.
[13] J. Wang, L. Zhao, H. Zhang, and W. Niu, "Research on optimization of urban drainage pipelines' carrying capacity based on SWMM model," China Rural Water and Hydropower, vol. 4, pp. 41-44, 2017.

[14] M. Shao, Z. Gong, and X. Xu, "Risk assessment of rainstorm and flood disasters in China between 2004 and 2009 based on gray fixed weight cluster analysis," Natural Hazards, vol. 71, no. 2, pp. 1025-1052, 2014.

[15] J. N. Goetz, R. H. Guthrie, and A. Brenning, "Forest harvesting is associated with increased landslide activity during an extreme rainstorm on Vancouver Island, Canada," Natural Hazards and Earth System Sciences, vol. 15, no. 6, pp. 1311-1330, 2015.

[16] H.-M. Lyu, G.-F. Wang, W.-C. Cheng, and S.-L. Shen, "Tornado hazards on June 23 in Jiangsu Province, China: preliminary investigation and analysis," Natural Hazards, vol. 85, no. 1, pp. 597-604, 2017.

[17] M. C. Strzelecki, A. J. Long, and J. M. Lloyd, "Post-little ice age development of a high arctic paraglacial beach complex," Permafrost and Periglacial Processes, vol. 28, no. 1, pp. 4-17, 2017.

[18] X. Liu, X. Li, and S. Dang, "Spatial pattern of precipitation change in the main sediment-yielding area of the Yellow river basin in recent years," Journal of Hydraulic Engineering, vol. 47, pp. 463-472, 2016.

[19] J. Li, S. Tan, Z. Wei, F. Chen, and P. Feng, "A new method of change point detection using variable fuzzy sets under environmental change," Water Resources Management, vol. 28, no. 14, pp. 5125-5138, 2014.

[20] Y. F. Ren, G. D. Liu, L. Zhou, and C. Zhang, "Risk evaluation of Chengdu's flood hazard based on evidence theory and variable fuzzy sets theory," Transactions of the Chinese Society of Agricultural Engineering, vol. 30, no. 21, pp. 147-156, 2014, in Chinese.

[21] P. Wang, "Research on the flood risk assessment of Guizhou based on information diffusion theory and data integration," China Rural Water and Hydropower, vol. 2, pp. 109-112, 2018, in Chinese.

[22] L. J. Zou, M. Zhong, X. H. Yang, and X. F. Liu, "Using information diffusion to analyze the membership degree in risk assessment of flash flood," Journal of Water Resources Research, vol. 5, pp. 598-604, 2016.

[23] E. Guo, J. Zhang, X. Ren, Q. Zhang, and Z. Sun, "Integrated risk assessment of flood disaster based on improved set pair analysis and the variable fuzzy set theory in central Liaoning Province, China," Natural Hazards, vol. 74, no. 2, pp. 947965, 2014.

[24] J. Chen, M. Deng, L. Xia, and H. Wang, "Risk assessment of drought, based on IDM-VFS in the Nanpan river basin, Yunnan Province, China," Sustainability, vol. 9, no. 7, p. 1124, 2017.

[25] X. Du, X. Jin, X. Yang, X. Yang, and Y. Zhou, "Spatial pattern of land use change and its driving force in Jiangsu province," International Journal of Environmental Research and Public Health, vol. 11, no. 3, pp. 3215-3232, 2014.

[26] T. L. Saaty, "Decision-making with the AHP: why is the principal eigenvector necessary," European Journal of Operational Research, vol. 145, no. 1, pp. 85-91, 2003.

[27] D. Zhao, Y. Zhang, and J. Ma, "Fuzzy risk assessment of entropy-weight coefficient method applied in network security," Computer Engineering, vol. 30, pp. 21-23, 2004.

[28] J. Xu, P. Feng, and P. Yang, "Research of development strategy on China's rural drinking water supply based on SWOTTOPSIS method combined with AHP-Entropy: a case in 
Hebei Province," Environmental Earth Sciences, vol. 75, no. 1, p. 58, 2016.

[29] L. J. Zhang, W. Li, and D. Y. Zhang, "Meteorological disaster risk assessment method based on information diffusion theory," Scientia Geographica Sinica, vol. 29, pp. 250-254, 2009.

[30] J. D. Wang and C. F. Huang, "Information diffusion method relevant in fuzzy information processing and its application," Journal of Northwest University, vol. 22, pp. 383-392, 1992.

[31] C. F. Huang, "Principle of information diffusion," Fuzzy Sets and Systems, vol. 91, no. 1, pp. 69-90, 1997.

[32] Q. Li, "Flood risk assessment based on the Information diffusion method," in Proceedings of the Advances in Computer Science, Environment, Ecoinformatics and Education, Springer, Berlin Heidelberg, German, pp. 111-117, August 2011.

[33] K. Nagata and S. Shirayama, "Method of analyzing the influence of network structure on information diffusion," Physica A: Statistical Mechanics and its Applications, vol. 391, no. 14, pp. 3783-3791, 2012.

[34] S. Y. Chen, "Theory and model of engineering variable fuzzy set-Mathematical basis for fuzzy hydrology and water resources," Journal of Dalian University of Technology, vol. 45, pp. 308-312, 2005.

[35] S. Huang, J. Chang, G. Leng, and Q. Huang, "Integrated index for drought assessment based on variable fuzzy set theory: a case study in the Yellow river basin, China," Journal of Hydrology, vol. 527, pp. 608-618, 2015.

[36] H. C. Zhou and Z. Dan, "Assessment model of drought and flood disasters with variable fuzzy set theory," Transactions of the Chinese Society of Agricultural Engineering, vol. 25, pp. 56-61, 2009.

[37] F. Denton, "Climate change vulnerability, impacts, and adaptation: why does gender matter?" Gender \& Development, vol. 10, no. 2, pp. 10-20, 2002.

[38] G. Hufschmidt, "A comparative analysis of several vulnerability concepts," Natural Hazards, vol. 58, no. 2, pp. 621-643, 2011.

[39] J. H. Danumah, S. N. Odai, B. M. Saley et al., "Flood risk assessment and mapping in Abidjan district using multicriteria analysis (AHP) model and geoinformation techniques, (Cote d'Ivoire)," Geoenvironmental Disasters, vol. 3, no. 1, p. 10, 2016.

[40] M. Hurlbert and J. Gupta, "The adaptive capacity of institutions in Canada, Argentina, and Chile to droughts and floods," Regional Environmental Change, vol. 17, no. 3, pp. 865-877, 2017.

[41] K. P. Dhakal and L. R. Chevalier, "Managing urban stormwater for urban sustainability: barriers and policy solutions for green infrastructure application," Journal of Environmental Management, vol. 203, pp. 171-181, 2017. 